\title{
Sequential gemcitabine and tamoxifen treatment enhances apoptosis and blocks transformation in bladder cancer cells
}

\author{
HISASHI TAKEUCHI, CHINEDU O. MMEJE, GOODWIN G. JINESH, RIKIYA TAOKA and ASHISH M. KAMAT \\ Department of Urology, The University of Texas MD Anderson Cancer Center, Houston, TX 77030, USA
}

Received June 5, 2015; Accepted June 25, 2015

DOI: $10.3892 /$ or.2015.4220

\begin{abstract}
Bladder cancer is a common malignancy for which regional or metastatic disease is identified at diagnosis. The aim of this study was to determine whether tamoxifen (Tam), an estrogen receptor (ER) antagonist, can sensitize bladder cancer cell lines to gemcitabine (Gem) chemotherapy. ER $\alpha$ and ER $\beta$ protein levels were determined in each cell line using western blot analysis. The TCC-Sup, 5637, and RT4 bladder cancer cells were exposed to various concentrations and regimens of Tam or Gem alone or in combination. Cell viability and apoptosis were assessed by 3-(4,5-dimethylthiazol-2-yl)-2,5-diphenyltetrazolium bromide assay and propidium iodide followed by flow cytometry. Apoptosis was then evaluated by western blot analysis. Treated TCC-Sup cells were subjected to soft agar colony formation assay to determine the cellular transformation. Western blot analysis results revealed ER expression in the three cell lines. TCC-Sup and 5637 cells treated with a combination of Tam and Gem had lower cell viabilities than those treated with Tam or Gem alone for $72 \mathrm{~h}$ in TCC-Sup and 5637. Compared with the other treatments, sequential Gem followed by Tam $(\mathrm{Gem} \rightarrow \mathrm{Tam})$ treatment caused the largest increase in DNA fragmentation at $72 \mathrm{~h}$ in TCC-Sup cells. Western blot analysis results revealed that this sequential Gem $\rightarrow$ Tam treatment increased poly(ADP-ribose) polymerase cleavage in TCC-Sup cells. Sequential Gem $\rightarrow$ Tam inhibited the cell transformation in TCC-Sup cells. In conclusion, sequential $\mathrm{Gem} \rightarrow \mathrm{Tam}$ enhanced the cytotoxicity of Gem in vitro. This regimen be useful to enhance the efficacy of Gem in bladder cancer. However, future in vivo studies are required to verify the results.
\end{abstract}

Correspondence to: Dr Hisashi Takeuchi, Department of Urology, Unit 1373, The University of Texas MD Anderson Cancer Center, 1515 Holcombe Boulevard, Houston, TX 77030, USA

E-mail: htakeuchi@mdanderson.org

Key words: cellular transformation, bladder cancer, chemotherapy, estrogen receptor, gemcitabine, tamoxifen

\section{Introduction}

Bladder cancer is the fourth most common malignancy in men and the ninth most common in women, with 74,690 cases being diagnosed in 2014 (1). Ten to $15 \%$ of patients present with regional or distant metastatic disease at diagnosis (2) and have 5-year survival rates of 33 and 5\%, respectively (3). Patients with muscle-invasive bladder cancer have a poor prognosis, often with survival of $<1$ year after metastasis to distant organs (4).

Metastatic bladder cancer is typically treated with various combinations of systemic chemotherapy (5). However, the majority of patients with metastatic bladder cancer succumb to the disease within 1-2 years (5). Gemcitabine (Gem), has been recognized for its activity against bladder cancer, and several novel combination regimens including Gem have been reported $(6,7)$. The combination of Gem and cisplatin has been shown to have similar efficacy to but lower toxicity than the standard combination treatment (methotrexate, vinblastine, doxorubicin, and cisplatin) (6). However, there is no compelling evidence of improved antitumor efficacy with the Gem plus cisplatin regimen. New agents that may increase the efficacy of cytotoxic chemotherapy for bladder cancer are needed.

Recent evidence suggests that bladder cancer has a molecular subtype that resembles breast cancer (8). Estrogen receptors (ERs) play a major role in breast cancer: ER $\alpha$ and ER $\beta$ belong to the same nuclear receptor superfamily and act as transcriptional factors to mediate important physiologic functions on regulating the growth of estrogen-responsive tumors in breast cancer $(9,10)$. Strong correlations between ER $\beta$ expression and bladder tumor grade and stage $(11,12)$ and between ER $\beta$ expression and worse progression-free survival rate have been identified in patients with bladder cancer. Additionally, it has been shown that patients with bladder cancer and high levels of ER $\beta$ have a worse progression-free survival rate than patients without this molecular subtype $(11,13)$. As women have a disproportionate incidence of bladder cancer and a worse prognosis than men, estrogen may play a role in bladder cancer incidence and invasion $(14,15)$.

Tamoxifen (Tam), a non-steroidal selective ER modulator that has strong efficacy against ER-positive breast tumors, may be an ideal synergic agent to increase the cytotoxic effects of Gem (16). We therefore hypothesized that Tam would enhance the cytotoxicity of Gem in human bladder cancer cell lines. 


\section{Materials and methods}

Cells and maintenance. The TCC-Sup and 5637 cells were kindly provided by Dr David J. McConkey (The University of Texas MD Anderson Cancer Center, Houston, TX), and RT4 cells were purchased from the American Type Culture Collection (ATCC; Manassas, VA, USA). The three cell lines were fingerprinted by the Characterized Cell Line Core of MD Anderson Cancer Center for the Specialized Program Of Research Excellence in Bladder Cancer. These cell lines were maintained as adherent cells in minimum essential medium (MEM) supplemented with $10 \%$ fetal bovine serum, penicillin, streptomycin, vitamins, glutamine, non-essential amino acids, and pyruvate at $37^{\circ} \mathrm{C}$ in a humidified atmosphere of $5 \% \mathrm{CO}_{2}$.

Reagents and antibodies. Tam (T9262) was obtained from Sigma-Aldrich (St. Louis, MO, USA). Gem was obtained from Sagent Pharmaceuticals (Schaumburg, IL, USA). Antibodies used for western blot analysis were purchased from the following manufacturers: poly(ADP-ribose) polymerase (PARP) (sc-7150) and caspase-3 (sc7148) (Santa Cruz Biotechnology, Inc., Dallas, TX, USA); ER $\alpha$ (2512) and p70 S6 kinase (p70S6K, 2708) (Cell Signaling Technology, Beverly, MA, USA); ER $\beta$ (ab3576; Abcam, Cambridge, MA, USA); and $\beta$-actin (A3853; Sigma-Aldrich). For the in vitro studies, Tam and Gem were reconstituted just before use in methanol and sterile water, respectively, creating stock solutions that were then diluted in medium to obtain the final concentrations indicated in the figures.

Evaluation of cell viability. Cells were seeded in a 96-well plate $\left(3 \times 10^{3}\right.$ cells/well) for $24 \mathrm{~h}$ and then treated with various concentrations of $\operatorname{Tam}(1,10$, or $20 \mu \mathrm{M})$ or Gem $(1 \mu \mathrm{M})$ alone or in combination for 24 to $72 \mathrm{~h}$. Cell viability was assessed by pulsing the cells for $2 \mathrm{~h}$ with 3-(4,5-dimethylthiazol-2-yl)-2,5-diphenyltetrazolium bromide (MTT) (from $5-\mathrm{mg} / \mathrm{ml}$ stock in phosphate-buffered saline solution). Formazan crystals were solubilized in lysis buffer $(100 \mu \mathrm{l})$ containing $20 \%$ sodium dodecyl sulfate and $50 \%$ dimethylformamide. Color development was quantified by measuring the optical densities at $570 \mathrm{~nm}$. The results are shown as means \pm SEM. Each experimental data point represents the mean value of four replicates, and each experiment was performed $\geq 2$ times.

Quantification of DNA fragmentation and flow cytometry. Cells were grown in 6-well plates in MEM. At $24 \mathrm{~h}$, the cells were sequentially treated with Gem $(1 \mu \mathrm{M})$ for $6 \mathrm{~h}$ and then Tam $(10 \mu \mathrm{M})(\mathrm{Gem} \rightarrow \mathrm{Tam})$ or Tam then Gem (Tam $\rightarrow \mathrm{Gem})$ for an additional 24-72 h. For comparison, the cells were treated with Tam or Gem alone, or were treated simultaneously (Tam+Gem). The cells were harvested by trypsinization and pelleted by centrifugation at 3,500 rpm for $5 \mathrm{~min}$. The cells were then resuspended in phosphate-buffered saline solution containing propidium iodide $(50 \mu \mathrm{g} / \mathrm{ml})$, with $0.1 \%$ Triton $\mathrm{X}-100$ and $0.1 \%$ sodium citrate. DNA fragmentation was measured using propidium iodide fluorescence-activated cell sorting (PI-FACS) (FC 500 flow cytometer; Beckman Coulter, Brea, CA, USA). Cells exhibiting hypodiploidy, indicative of DNA fragmentation, were scored as apoptotic. PI-FACS analysis was performed in triplicate, and the results are shown as the mean percentage of fragmentation \pm SEM.

Western blot analysis. After plating TCC-Sup and 5637 cells, the cells were treated with the same combinations agents used in the flow cytometry experiments. The cells were scraped in medium at $24 \mathrm{~h}$, pelleted by centrifugation at 3,500 rpm for $5 \mathrm{~min}$, washed once with ice-cold phosphate-buffered saline solution, and re-pelleted by centrifugation at 3,500 rpm for $5 \mathrm{~min}$. The pellets were subjected to lysis buffer [50 $\mathrm{mM}$ of Tris-HCl, pH 7.4; $150 \mathrm{mM}$ of sodium chloride; $5 \mathrm{mM}$ of ethylenediaminetetraacetic acid; $25 \mathrm{mM}$ of sodium fluoride; $1 \%$ Triton X-100; $1 \%$ NP-40; $0.1 \mathrm{mM}$ of sodium orthovanadate; $12.5 \mathrm{mM}$ of $\beta$-glycerophosphate; $1 \mathrm{mM}$ of phenylmethylsulfonyl fluoride; and complete protease inhibitor cocktail (Roche, Basel, Switzerland)] and were clarified at 13,000 rpm for $10 \mathrm{~min}$ at $4^{\circ} \mathrm{C}$. The supernatants were measured and subjected to sodium dodecyl sulfate-polyacrylamide gel electrophoresis and western blotting on a nitrocellulose membrane. The blots were developed using ECL reagent (GE Healthcare, Pittsburgh, PA, USA). Equal protein loading was confirmed using $\beta$-actin blots.

Soft agar colony formation/transformation assay. TCC-Sup cells were grown to semi-confluence in $10-\mathrm{cm}$ plates and were treated with MEM, methanol, and Tam $(10 \mu \mathrm{M})$ or Gem $(1 \mu \mathrm{M})$ alone or with sequential Gem $\rightarrow$ Tam for $72 \mathrm{~h}$. The cells were then subjected to trypsinization and were counted. TCC-Sup cells $\left(5 \times 10^{3}\right.$ cells $\left./ \mathrm{ml}\right)$ were then seeded in 6 -well plates in MEM with $0.5 \%$ agarose or were layered on top of $0.4 \%$ agar in MEM in 6-well plates (for the soft agar assay). The plates were incubated at $37^{\circ} \mathrm{C}$ in a humidified atmosphere of $5 \% \mathrm{CO}_{2}$. After 2 weeks, the cells were stained with MTT $(5 \mathrm{mg} / \mathrm{ml})$, and cell colonies were counted and photographed on the stage of Desk Top Light Box (Logan Electric, Texarkana, AR, USA) using Canon IXY120 (Tokyo, Japan).

Statistical analysis. Statistical analysis was performed using Ekuseru-Toukei 2010 software (Social Survey Research Information Co., Ltd., Tokyo, Japan). Analysis of variance and the Student's t-test were used to evaluate statistical significance of differences between cells treated at each drug concentration and untreated control cells. These data were normal distributed. $\mathrm{P}<0.05$ was considered statistically significant.

\section{Results}

ER expression in bladder cancer cell lines. Immunoblotting results for RT4, 5637, and TCC-Sup cells revealed that RT4 cells had no ER $\alpha$ expression than TCC-Sup and 5637 cells. However, the three cell lines expressed $\operatorname{ER} \beta$, with the highest levels in TCC-Sup cells (Fig. 1).

Effects of Tam and Gem on cell viability. We examined the effects of Gem or Tam alone and simultaneous treatment on the viability of the three cell lines. On the MTT assay, cell viability was affected by the two agents in a concentration-dependent manner (Fig. 2). Tam (10 $\mu \mathrm{M})$ alone treatment for $72 \mathrm{~h}$ reduced the viability of TCC-Sup, 5637, and RT4 cells to 36.4, 40.6, and $45.5 \%$, respectively, of the viability of untreated control 


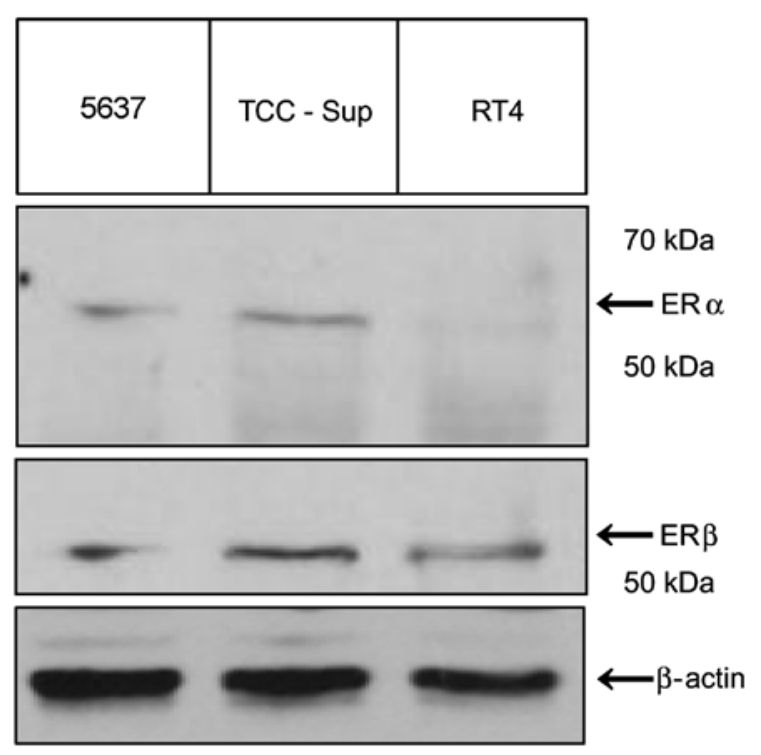

Figure 1. ER expression of three bladder cancer cell lines. We performed western blot analysis of ERs $\alpha$ and $\beta$ (ER $\alpha$ and $E R \beta)$ in human bladder cancer cell lines. Expression of ER $\alpha$ (top panel), ER $\beta$ (middle panel), and $\beta$-actin (bottom panel) were assessed in extracts prepared from TCC-Sup, 5637, and RT4 bladder cancer cell lines. ER, estrogen receptor.

cells (Fig. 2). The three cell lines treated with the highest dose of Tam $(20 \mu \mathrm{M})$ alone had a significantly lower cell viability than the controls, regardless of treatment time $24 \mathrm{~h}$ : [TCC-Sup cells, 1.9\%; 5637 cells, $11.9 \%$; RT4 cells, $6.2 \%$; $(\mathrm{P}<0.05) 48 \mathrm{~h}$ : TCC-Sup cells, 5.2\%; 5637 cells, 12.4\%; RT4 cells, 17.9\%;
( $\mathrm{P}<0.05) ; 72$ h: TCC-Sup cells, 1.2\%; 5637 cells, 4.1\%; RT4 cells, 7.4\%; (P<0.05)] (Fig. 2). At the 72-h time-point, Gem $(1 \mu \mathrm{M})$ reduced the viability of TCC-Sup, 5637, and RT4 cells to $30.5,21.0$, and $21.1 \%$, respectively $(\mathrm{P}<0.05)$.

TCC-Sup and 5637 cells treated with simultaneous Gem $(1 \mu \mathrm{M})+$ Tam $(1$ or $10 \mu \mathrm{M})$ had a significantly lower cell viability than those treated with Gem or Tam alone for $72 \mathrm{~h}$ [TCC-Sup cells: Tam $(1 \mu \mathrm{M})+$ Gem $(1 \mu \mathrm{M}), 17.3 \%$; Tam $(10 \mu \mathrm{M})+$ Gem $(1 \mu \mathrm{M}), 6.7 \%(\mathrm{P}<0.05) ; 5637$ cells: Tam $(1 \mu \mathrm{M})+\operatorname{Gem}(1 \mu \mathrm{M}), 14.6 \%$; Tam $(10 \mu \mathrm{M})+\operatorname{Gem}(1 \mu \mathrm{M})$, $8.8 \%(\mathrm{P}<0.05)]$ (Fig. 2).

However, simultaneous treatment did not significantly affect cell viability in comparison with Tam or Gem alone in RT4 cells after $72 \mathrm{~h}$ of treatment [RT4 cells: Tam $(1 \mu \mathrm{M})+$ Gem $(1 \mu \mathrm{M}), 20.1 \%$; Tam $(10 \mu \mathrm{M})+\operatorname{Gem}(1 \mu \mathrm{M}), 22.4 \%]$.

These results demonstrated that high concentrations of Tam produced substantial cytotoxic effects in the three cell lines. Treating cells with simultaneous Tam+Gem increased cytotoxicity with lower concentrations of Tam.

Effect of sequential treatment on DNA fragmentation. We examined the apoptosis-inducing effects of sequential of Gem and Tam treatment in the three cell lines. In TCC-Sup and 5637 cells in response to sequential Gem and Tam treatment, an increase in DNA fragmentation was consistently observed with treatment periods $>24 \mathrm{~h}$ (Fig. 3A and B). TCC-Sup and 5637 cells treated with sequential Tam $(10 \mu \mathrm{M}) \rightarrow \operatorname{Gem}(1 \mu \mathrm{M})$ or Gem $(1 \mu \mathrm{M}) \rightarrow \operatorname{Tam}(10 \mu \mathrm{M})$ had greater DNA fragmentation than those treated with Gem or Tam alone at the 72-h time-point (TCC-Sup, 10.6\%; 5637, 7.8\%; P<0.05) (Fig. 3A and B).
A

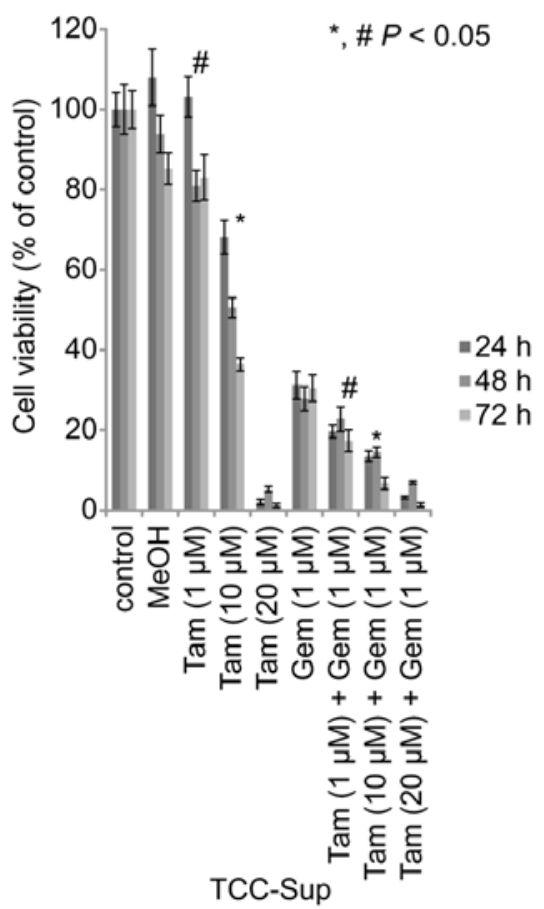

B
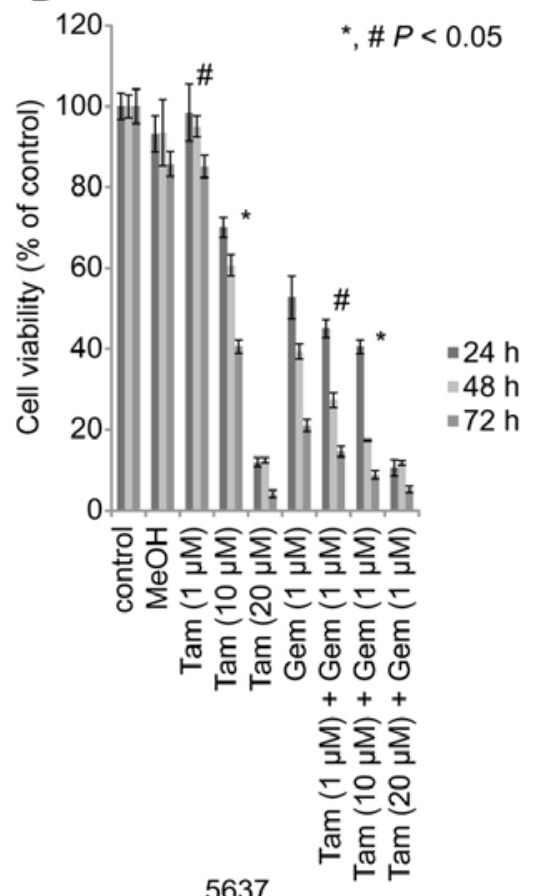

C

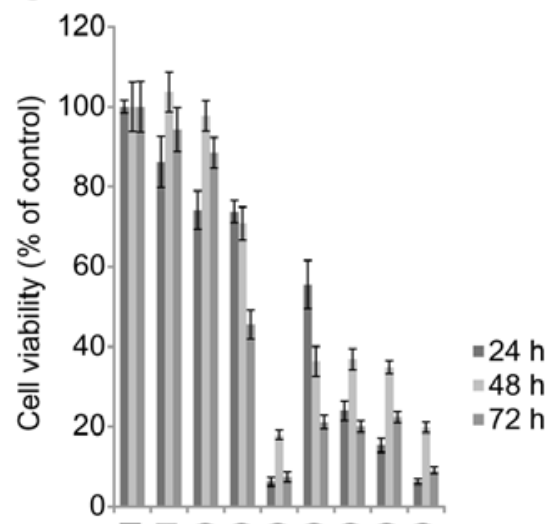

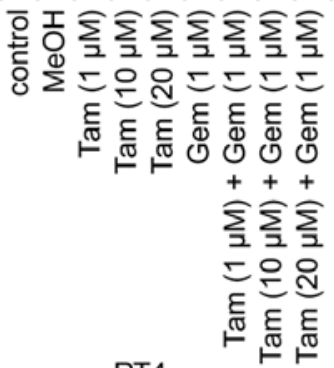

RT4

Figure 2. Cell viability of three bladder cancer cell lines after treatment with Tam or Gem alone or in combination. MTT assay shows inhibition of viability in TCC-Sup, 5637, and RT4 bladder cancer cells treated with Gem or Tam alone or in combination. Cell viability analysis of (A) TCC-Sup, (B) 5637, and (C) RT4 bladder cancer cell lines treated with various concentrations of Tam (1, 10, or $20 \mu \mathrm{M})$ or Gem (1 $\mu \mathrm{M})$ alone or simultaneous Gem and Tam for $24-72 \mathrm{~h}$.

${ }^{*}, \# \mathrm{P}<0.05$, statistically significant. Tam, tamoxifen; Gem, gemcitabine. 

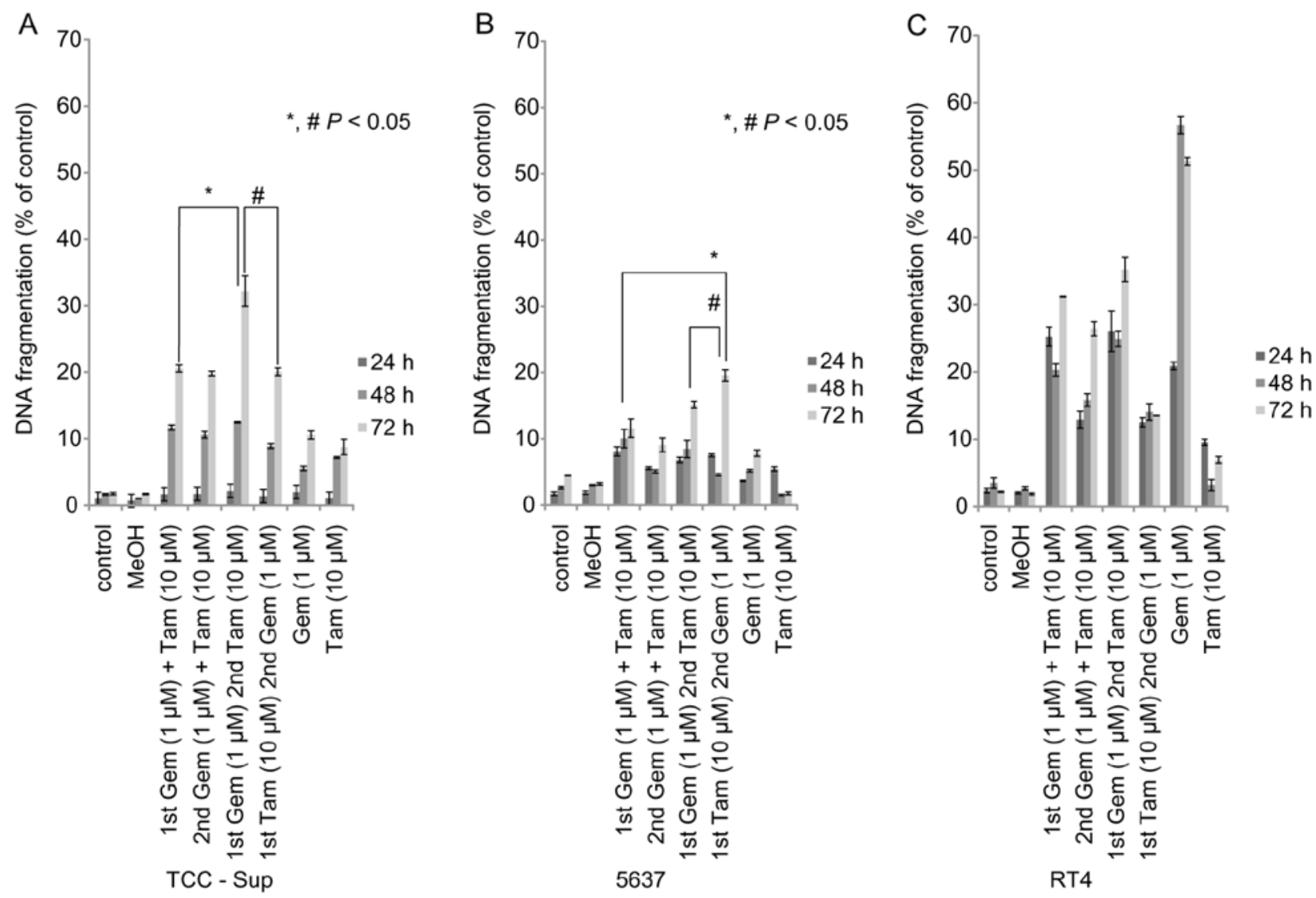

Figure 3. Sequential gemcitabine and tamoxifen increases apoptosis in bladder cancer cells. The effects of sequential Gem and Tam treatment on apoptosis measured by PI-FACS. DNA fragmentation of (A) TCC-Sup, (B) 5637, and (C) RT4 bladder cancer cell lines following sequential treatment with Gem $(1 \mu \mathrm{M})$ for $6 \mathrm{~h}$ and then Tam $(10 \mu \mathrm{M})(\mathrm{Gem} \rightarrow \mathrm{Tam})$ for an additional 24-72 $\mathrm{h}$ or vice versa. For comparison purposes, the cells were treated with Tam or Gem alone or were simultaneously treated (Gem+Tam). ${ }^{*, \#} \mathrm{P}<0.05$, statistically significant. Gem, gemcitabine; Tam, tamoxifen; PI-FACS, propidium iodide fluorescence-activated cell sorting.

Sequential Gem $\rightarrow$ Tam treatment resulted in greater DNA fragmentation $(32.2 \%)$ than simultaneous Gem+Tam (20.1\%) or sequential Tam $\rightarrow$ Gem (20.1\%) in TCC-Sup cells (Fig. 3A). DNA fragmentation was slightly higher in 5637 cells treated with sequential Tam $\rightarrow \mathrm{Gem}(19.6 \%)$ than in those treated with simultaneous Gem+Tam (11.6\%) or sequential Gem $\rightarrow$ Tam (15.1\%) (Fig. 3B).

However, RT4 cells treated with sequential Tam $\rightarrow$ Gem or $\mathrm{Gem} \rightarrow \mathrm{Tam}$ had lower DNA fragmentation than those treated with Gem alone at the 48- and 72-h time-points (Fig. 3C). In RT4 cells, Gem alone induced a high amount of DNA fragmentation ( $48 \mathrm{~h}, 56.7 \%$ ), which did not differ from the DNA fragmentation in RT4 cells treated with either sequential Tam $\rightarrow$ Gem or Gem $\rightarrow$ Tam.

These results demonstrate that sequential Gem $\rightarrow$ Tam or $\mathrm{Tam} \rightarrow \mathrm{Gem}$ induced apoptosis to a greater extent than Gem or Tam alone or simultaneous treatment in TCC-Sup and 5637 cells, and these effects of sequential treatment in TCC-Sup were higher than in 5637 (Fig. 3A and B). These findings also indicate that TCC-Sup and 5637 cells are resistant to Gem therapy whereas RT4 cells are not resistant to Gem therapy.

Expression of markers of apoptosis and cell transformation. To confirm that the cytotoxic effects of sequential therapy in TCC-Sup and 5637 cells were associated with apoptosis and reduced cell transformation, we performed western blot analysis to assess the expression of cleaved caspase- 3 as an apoptosis markers and the cell transformation of cleaved PARP and p70S6K as markers in treated cells. Caspase and PARP cleavage marked apoptosis whereas the expression of p70S6K marked the ability of cells to form spheres (transformation) after apoptosis (17). TCC-Sup cells treated with sequential $\mathrm{Gem} \rightarrow$ Tam for $72 \mathrm{~h}$ had lower levels of full-length PARP, p70S6K, and procaspase- 3 and had higher levels of cleaved PARP than the controls (Fig. 4A). The expression levels of the apoptotic markers were lower in 5637 cells treated with the regimen, including the Tam $\rightarrow$ Gem sequence (Fig. 4B). Notably, p70S6K was downregulated by sequential Gem $\rightarrow$ Tam treatment in TCC-Sup cells (Fig. 4A) at the 72-h time-point, indicating that sequential treatment may inhibit cell transformation. Taken together, these data demonstrated that sequential Gem $\rightarrow$ Tam treatment enhanced PARP cleavage and downregulated p70S6K in TCC-Sup cells.

Inhibition of cell transformation by sequential Gem $\rightarrow$ Tam treatment in TCC-Sup cells. Since p70S6K was downregulated by sequential Gem $\rightarrow$ Tam treatment in TCC-Sup cells, we performed soft agar colony formation assays to determine the effects of these agents on cellular transformation in TCC-Sup cells. Cells treated with sequential $\mathrm{Gem} \rightarrow \mathrm{Tam}$ had signifi- 

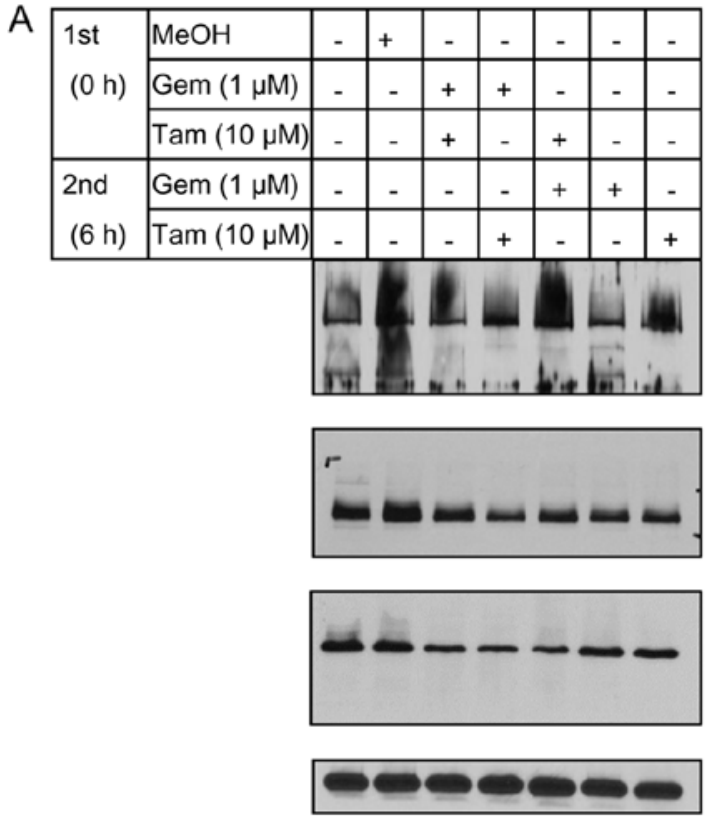

$0-48 \mathrm{~h}$

B
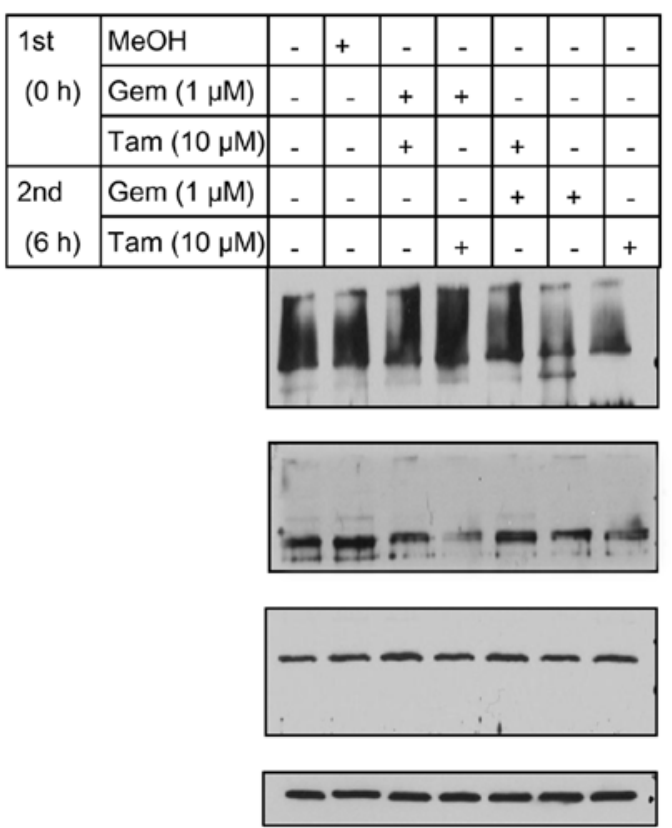

$0-48 \mathrm{~h}$
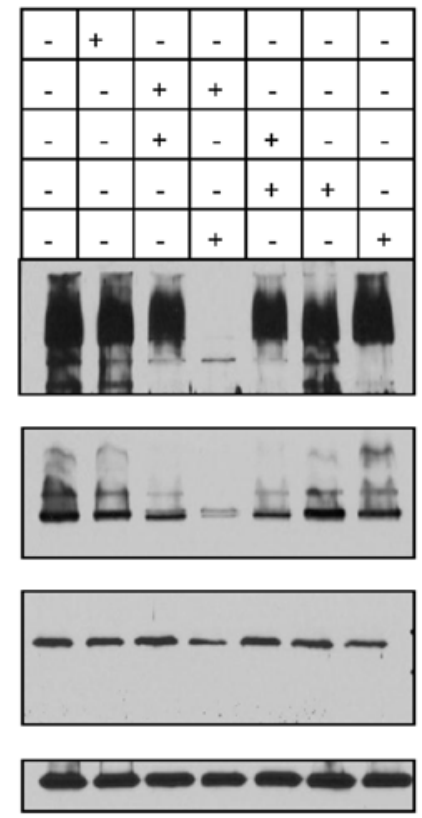

$0-72 \mathrm{~h}$

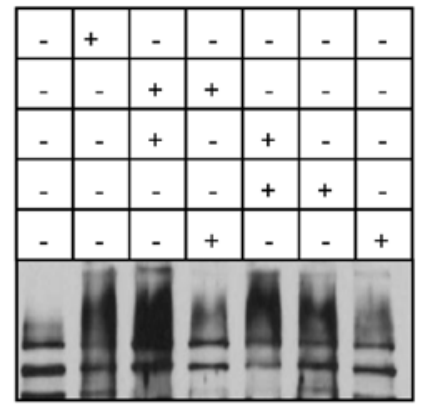

PARP

Full - length PARP

Cleaved PARP

p70s6K

$70 \mathrm{kDa}$

$50 \mathrm{kDa}$

procaspase-3

$25 \mathrm{kDa}$

$\beta$ - actin

Figure 4. Sequential gemcitabine and tamoxifen inhibits cell transformation in bladder cancer cells. Apoptosis is confirmed by PARP, caspase-3, and p70 S6 kinase (p70S6K) expression patterns using western blotting in (A) TCC-Sup and (B) 5637 bladder cancer cell lines. Cells were treated with sequential Gem $(1 \mu \mathrm{M})$ for $6 \mathrm{~h}$ and then Tam $(10 \mu \mathrm{M})(\mathrm{Gem} \rightarrow \mathrm{Tam})$ for an additional $24-72 \mathrm{~h}$, or vice versa (Tam $\rightarrow \mathrm{Gem})$, Tam or Gem alone, or simultaneous treatment for 48 and $72 \mathrm{~h}$. Note that sequential Gem $\rightarrow$ Tam in TCC-Sup for $72 \mathrm{~h}$ induced PARP cleavage/reduction and p70S6K reduction. Gem, gemcitabine; Tam, tamoxifen; PARP, poly(ADP-ribose) polymerase.

cantly less transformation (2.4\%) than those treated with Tam $(59.3 \%)$ or Gem (15.9\%) alone (P<0.05, Fig. 5A). These results demonstrated that sequential Gem $\rightarrow$ Tam treatment effectively inhibited cell transformation.

\section{Discussion}

In the present study, we found TCC-Sup and 5637 cells were resistant to Gem therapy whereas RT4 cells were not resistant to Gem therapy. However, the sequential treatment of Gem and Tam enhanced apoptosis in TCC-Sup and 5637 cells. Sequential Gem followed by Tam $(\mathrm{Gem} \rightarrow \mathrm{Tam})$ treatment caused the largest increase in DNA fragmentation at $72 \mathrm{~h}$ in TCC-Sup cells compared to the other treatments in the remaining two cell lines, and this regimen enhanced PARP cleavage and downregulated p70S6K and blocked transformation in bladder cancer cells.

Our results demonstrate that Tam induced significant apoptosis when treated in sequence after gemcitabine with prolonged incubation in a cell type-dependent manner. Bladder 


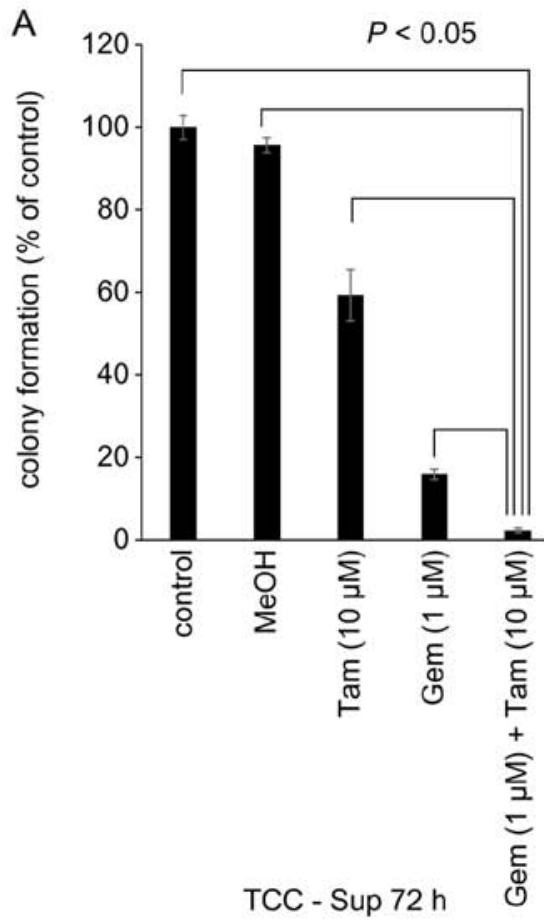

B
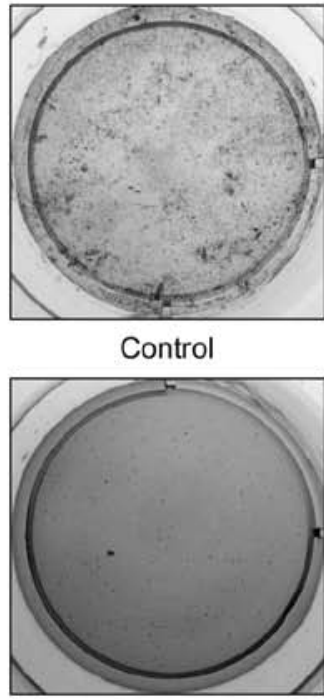

Gemcitabine $(1 \mu \mathrm{M})$

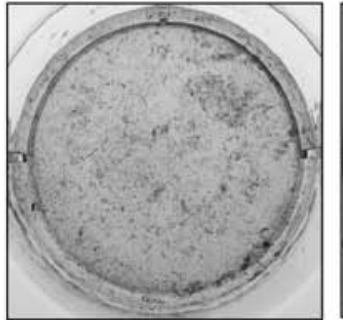

$\mathrm{MeOH}$

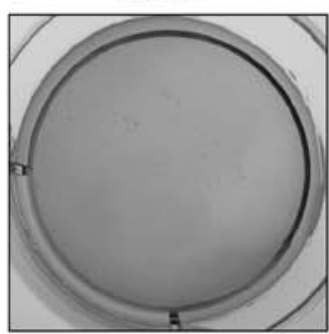

Gemcitabine $(1 \mu \mathrm{M})+$ Tamoxifen $(10 \mu \mathrm{M})$

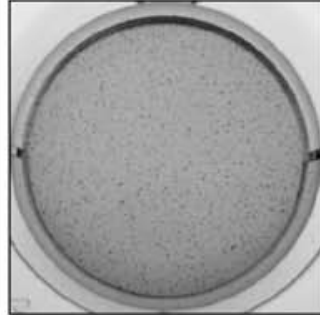

Tamoxifen $(10 \mu \mathrm{M})$

TCC - Sup 72 h

Figure 5. Inhibition of cellular transformation in bladder cancer cells by sequential gemcitabine and tamoxifen is confirmed in soft agar colony formation assay. (A and B) Soft agar colony formation assay demonstrates the inhibitory effects of sequential Gem and Tam treatment on cell transformation in TCC-Sup cells. Sequential treatment with Gem $(1 \mu \mathrm{M})$ for $6 \mathrm{~h}$ and then Tam $(10 \mu \mathrm{M})(\mathrm{Gem} \rightarrow \mathrm{Tam})$ for $72 \mathrm{~h}$ significantly reduced cell transformation (sphere formation). Gem, gemcitabine; Tam, tamoxifen.

cancer is shown to have similarities to breast cancer in terms of gene expression data profiling (8). Breast cancer is known to have therapeutic efficiency based on ER expression. Thus, we examined whether bladder cancer cells express ERs or not. This cell-type dependency likely reflects the expression of of ERs for the cell lines. TCC-Sup and 5637 cells, which had the higher ER $\beta$ levels, had more resistance to apoptosis when treated with Gem alone than RT4 cells, which had lower levels of ER $\beta$ than TCC-Sup and 5637 cells. Our findings support those of Shen et al (12) who reported that ER $\beta$ expression occurred more frequently in high-grade bladder cancers and significantly more often in muscle-invasive and metastatic bladder cancers. Shen et al (12) suggested that ER $\beta$ possibly plays a role in tumor progression and metastasis, possibly by conferring a growth advantage.

TCC-Sup cells is a bladder cancer cell line that exhibits metastasis and cell transformation and 5637 cells exhibit invasiveness, whereas RT4 bladder cell lines represent papillary tumor. Our findings showing that TCC-Sup and 5637 cells are resistant to Gem reflect the clinical outcomes of patients with metastatic or invasive bladder cancer. These patients are typically treated with systemic chemotherapy regimens that include Gem, although the median progression-free and overall survival durations are only 7.7 and 14.0 months, respectively (18). Regimens that increase the efficiency of Gem are needed to improve patient outcomes.

Gem is a nucleoside analogue that interferes with DNA synthesis to induce apoptosis (19). Tam is a standard endocrine therapy for the treatment of steroid receptor-positive breast cancer $(20,21)$. Our results support those of another study which found that Tam treatment inhibited bladder cancer cell proliferation (12). In the present study, Tam alone showed significant cytotoxic effects in the three cell lines, but only at high concentrations. Combining Tam with Gem resulted in increased cytotoxicity at lower concentrations.

Our results show that the sequential treatment exerted significant apoptotic effects in TCC-Sup and 5637 cells, which showed resistance to Gem alone. Previous findings have suggested that combining Gem and Tam is a valid and effective therapy for advanced breast cancer, (22). Additionally, the efficacy of this combination treatment in breast cancer was previously demonstrated (23). Sequential Gem $\rightarrow$ Tam treatment resulted in greater DNA fragmentation in TCC-Sup cells, whereas Tam $\rightarrow$ Gem treatment resulted in greater DNA fragmentation in 5637 cells. However, the effects level of sequential treatment itself resulted in greater DNA fragmentation in TCC-Sup cells than in 5637 cells. Therefore, the results of the present study have effectively shown the significance of utilizing this drug schedule (Gem $\rightarrow$ Tam) in TCC-Sup. Our results demonstrate that sequential treatment for $72 \mathrm{~h}$ effectively induced TCC-Sup cell death through apoptosis. Several studies have investigated ER $\alpha$ and ER $\beta$ protein levels in bladder cancer development and have found correlations between ER expression and bladder cancer stage $(11-13,24)$, which underscores the importance of targeting ERs in bladder cancer therapy.

There is also a possibility of sequential treatment using Gem and Tam in metastastic bladder cancer. However, we were not able to determine the usefulness of this treatment, including clinical background. Our results have demonstrated that sequential Gem $\rightarrow$ Tam treatment effectively inhibited cell transformation in TCC-Sup cells. Previous findings showed that apoptotic cells expressing p70S6K are capable of undergoing cell transformation (sphere formation) (17). We found 
that the sequential Gem $\rightarrow$ Tam treatment reduced p70S6K expression, which efficiently inhibited cell transformation in TCC-Sup cells. Thus, our study identified a viable sequential treatment strategy in vitro that remains to be confirmed via in vivo studies.

In conclusion, prolonged sequential Gem $\rightarrow$ Tam treatment induced significant apoptosis in a bladder cancer cell type-dependent manner and inhibited cell transformation. This sequential treatment may be useful in the increase of the efficiency of Gem against bladder cancer in a subset of patients and should be investigated.

\section{Acknowledgements}

The authors would like to thank the Department of Scientific Publications, The University of Texas MD Anderson Cancer Center for the English Language Review. This study was supported in part by the National Institutes of Health through MD Anderson Cancer Center's Support Grant, CA016672.

\section{References}

1. DeSantis CE, Lin CC, Mariotto AB, Siegel RL, Stein KD, Kramer JL, Alteri R, Robbins AS and Jemal A: Cancer treatment and survivorship statistics, 2014. CA Cancer J Clin 64: 252-271, 2014.

2. Rosenberg JE, Carroll PR and Small EJ: Update on chemotherapy for advanced bladder cancer. J Urol 174: 14-20, 2005.

3. Stein JP, Lieskovsky G, Cote R, Groshen S, Feng AC, Boyd S, Skinner E, Bochner B, Thangathurai D, Mikhail M, et al: Radical cystectomy in the treatment of invasive bladder cancer: Long-term results in 1,054 patients. J Clin Oncol 19: 666-675, 2001 .

4. Galsky MD, Moshier E, Krege S, Lin CC, Hahn N, Ecke T, Sonpavde G, Godbold J, Oh WK and Bamias A: Nomogram for predicting survival in patients with unresectable and/or metastatic urothelial cancer who are treated with cisplatin-based chemotherapy. Cancer 119: 3012-3019, 2013.

5. Sternberg CN, Yagoda A, Scher HI, Watson RC, Geller N, Herr HW, Morse MJ, Sogani PC, Vaughan ED, Bander N et al: Methotrexate, vinblastine, doxorubicin, and cisplatin for advanced transitional cell carcinoma of the urothelium. Efficacy and patterns of response and relapse. Cancer 64: 24482458, 1989.

6. von der Maase H, Hansen SW, Roberts JT, Dogliotti L, Oliver T, Moore MJ, Bodrogi I, Albers P, Knuth A, Lippert CM, et al: Gemcitabine and cisplatin versus methotrexate, vinblastine, doxorubicin, and cisplatin in advanced or metastatic bladder cancer: Results of a large, randomized, multinational, multicenter, phase III study. J Clin Oncol 18: 3068-3077, 2000.

7. Hussain M, Vaishampayan U, Du W, Redman B and Smith DC: Combination paclitaxel, carboplatin, and gemcitabine is an active treatment for advanced urothelial cancer. J Clin Oncol 19: 2527-2533, 2001.
8. Choi W,Porten S,KimS, Willis D,PlimackER,Hoffman-Censits J, Roth B, Cheng T, Tran M, Lee IL, et al: Identification of distinct basal and luminal subtypes of muscle-invasive bladder cancer with different sensitivities to frontline chemotherapy. Cancer Cell 25: 152-165, 2014.

9. Nilsson S, Mäkelä S, Treuter E, Tujague M, Thomsen J, Andersson G, Enmark E, Pettersson K, Warner $M$ and Gustafsson JA: Mechanisms of estrogen action. Physiol Rev 81: 1535-1565, 2001.

10. Harris HA: Estrogen receptor-beta: Recent lessons from in vivo studies. Mol Endocrinol 21: 1-13, 2007.

11. Miyamoto H, Yao JL, Chaux A, Zheng Y,Hsu I, Izumi K, Chang C, Messing EM, Netto GJ and Yeh S: Expression of androgen and oestrogen receptors and its prognostic significance in urothelial neoplasm of the urinary bladder. BJU Int 109: 1716-1726, 2012.

12. Shen SS, Smith CL, Hsieh JT, Yu J, Kim IY, Jian W, Sonpavde G, Ayala GE, Younes M and Lerner SP: Expression of estrogen receptors-alpha and -beta in bladder cancer cell lines and human bladder tumor tissue. Cancer 106: 2610-2616, 2006.

13. Tuygun C, Kankaya D, Imamoglu A, Sertcelik A, Zengin K, Oktay $\mathrm{M}$ and Sertcelik N: Sex-specific hormone receptors in urothelial carcinomas of the human urinary bladder: A comparative analysis of clinicopathological features and survival outcomes according to receptor expression. Urol Oncol 29: 43-51, 2011.

14. Pfister C: New trends for optimal management of bladder tumors. J Urol 165: 65-66, 2001.

15. Jemal A, Bray F, Center MM, Ferlay J, Ward E and Forman D: Global cancer statistics. CA Cancer J Clin 61: 69-90, 2011.

16. Zheng A, Kallio A and Härkönen P: Tamoxifen-induced rapid death of MCF-7 breast cancer cells is mediated via extracellularly signal-regulated kinase signaling and can be abrogated by estrogen. Endocrinology 148: 2764-2777, 2007.

17. Jinesh GG, Choi W, Shah JB, Lee EK, Willis DL and Kamat AM: Blebbishields, the emergency program for cancer stem cells: Sphere formation and tumorigenesis after apoptosis. Cell Death Differ 20: 382-395, 2013.

18. von der Maase H, Sengelov L, Roberts JT, Ricci S, Dogliotti L, Oliver T, Moore MJ, Zimmermann A and Arning M: Long-term survival results of a randomized trial comparing gemcitabine plus cisplatin, with methotrexate, vinblastine, doxorubicin, plus cisplatin in patients with bladder cancer. J Clin Oncol 23: 4602-4608, 2005.

19. Huang P, Chubb S, Hertel LW, Grindey GB and Plunkett W: Action of 2',2'-difluorodeoxycytidine on DNA synthesis. Cancer Res 51: 6110-6117, 1991.

20. Brauch H and Jordan VC: Targeting of tamoxifen to enhance antitumour action for the treatment and prevention of breast cancer: The 'personalised' approach? Eur J Cancer 45: 2274-2283, 2009.

21. Marshall E: Tamoxifen. 'A big deal,' but a complex hand to play. Science 280: 196, 1998.

22. Silvestris N, Cinieri S, La Torre I, Pezzella G, Numico G, Orlando L and Lorusso V: Role of gemcitabine in metastatic breast cancer patients: A short review. Breast 17: 220-226, 2008.

23. Cosco D, Paolino D, Cilurzo F, Casale F and Fresta M: Gemcitabine and tamoxifen-loaded liposomes as multidrug carriers for the treatment of breast cancer diseases. Int J Pharm 422: 229-237, 2012.

24. Han B, Cui D, Jing Y, Hong Y and Xia S: Estrogen receptor $\beta$ $(\mathrm{ER} \beta)$ is a novel prognostic marker of recurrence survival in non-muscle-invasive bladder cancer potentially by inhibiting cadherin switch. World J Urol 30: 861-867, 2012. 